\title{
The Impact of Urban Recreation Environment on Residents' Happiness-Based on a Case Study in China
}

\author{
Lei Kang ${ }^{1,2}\left(\mathbb{D}\right.$, Zhaoping Yang ${ }^{1,2, *}$ and Fang Han ${ }^{1,2}$ \\ 1 State Key Laboratory of Desert and Oasis Ecology, Xinjiang Institute of Ecology and Geography, Chinese \\ Academy of Sciences, Urumqi 830011, China; kanglei16@mails.ucas.ac.cn (L.K.); hanfang@ms.xjb.ac.cn (F.H.) \\ 2 University of Chinese Academy of Sciences, Beijing 100049, China \\ * Correspondence: yangzp@ms.xjb.ac.cn; Tel.: +86-991-788-5349
}

Citation: Kang, L.; Yang, Z.; Han, F. The Impact of Urban Recreation Environment on Residents' Happiness-Based on a Case Study in China. Sustainability 2021, 13, 5549. https://doi.org/10.3390/su13105549

Academic Editor: Juan

Ignacio Pulido-Fernández

Received: 2 April 2021

Accepted: 12 May 2021

Published: 16 May 2021

Publisher's Note: MDPI stays neutra with regard to jurisdictional claims in published maps and institutional affiliations.

Copyright: (C) 2021 by the authors Licensee MDPI, Basel, Switzerland This article is an open access article distributed under the terms and conditions of the Creative Commons Attribution (CC BY) license (https:// creativecommons.org/licenses/by/ $4.0 /)$.
Abstract: Rapid urbanization promotes the expansion of urban tourism and recreation functions, but it also brings many problems, which affect residents' happiness. Previous studies have emphasized the direct impact of urban recreation environment on happiness, and few have explored the indirect impact of urban recreation environment on happiness through subjective evaluation. Based on the survey data of nearly 10,000 permanent residents in 40 key tourism cities in China, this paper establishes a theoretical framework of the direct and indirect impact of urban recreation environment on happiness. The objective evaluation of natural recreation environment and sociocultural recreation environment has an important influence on happiness, but the influence of natural recreation environment is greater than that of sociocultural recreation environment. Individual subjective satisfaction with urban recreation environment mediates the relationship between urban objective environment and happiness. Urban parks have a positive effect on happiness, while tourist attractions have a negative effect. The influence of urban location on happiness is nonlinear. The high-income group is more sensitive to the recreation environment, while the low-income group is less sensitive to the recreation environment. These findings provide insights for further improving citizens' quality of life and designing urban construction in developing countries under the conditions of rapid urbanization.

Keywords: recreation environment; happiness; satisfaction; SEM; 40 cities; China

\section{Introduction}

Over the last 30 years, China's urbanization process has been developing rapidly. Rapid urbanization has promoted the transformation of urban functions and the recreation function of cities has gradually become the mainstream [1]. In parallel with the rapid development of urban economies, people's leisure time is increasing gradually, and urban transportation tends to be more convenient, which makes urban residents expect more diversified recreation space. However, high-quality recreation areas are becoming increasingly scarce resources. The real estate industry and tourism continue to occupy the public recreation space of urban residents, and it is increasingly difficult to take into account the interests of local residents in the space production of tourism cities [2]. Local residents' lack of public entertainment places is becoming increasingly serious. Therefore, the planning, construction, optimization and upgrading of the urban recreation environment has become an important issue for realizing sustainable development and building a "harmonious and livable city" in the process of urbanization in China [3].

Recreation and leisure activities are important sources of happiness. The Charter of Athens, adopted at the fourth Conference of the International Association of Modern Architects in 1933, included "recreation" as the main function of the city for the first time [4]. This is the development stage of functional leisure and recreation in the urbanization stage. The recreation environment has gradually become one of the core factors affecting the development of the urban living environment. Urbanization promotes the development of 
the urban recreation environment, and the planning and construction of the urban recreation environment also play a positive role in promoting the urbanization transformation and upgrading and the construction of livable cities $[5,6]$. From the stage of urbanization development, urbanization transformation and livable city construction are closely related to the urban recreation environment that reflects residents' quality of life. City dwellers are the main living groups living in cities. The happiness of urban residents is an important reflection of the quality of urban development, and also an important guarantee to promote the healthy development of cities [7].

Happiness research has become a hot topic in current research. Gross National Happiness $(\mathrm{GNH})$, promoted by countries such as Bhutan, has attracted much international attention. In 2012, the United Nations released its World Happiness Report for the first time, bringing the topic of happiness into the public consciousness. Happiness has always been a subject discussed and studied by economics and geography [8]. The field of economics focuses on the impact of urban economic attributes such as income, unemployment and inflation on happiness [9,10]. Geography studies on happiness mainly focus on the comprehensive evaluation of happiness, regional differences and so on. The research on the influence of various geographical factors on happiness is also extensive, and the urban recreation environment also has a very important influence on happiness. For example, a large number of studies have pointed out that there are significant effects on happiness in the main aspects of temperature, urban location, built environment and service facilities [11-13]. Few studies have explored the relationship between urban recreation environment and happiness from the perspective of urban recreation environment. In addition, most studies have focused on the measurement of the urban objective environment. There is a lack of research from the level of residents' subjective perception. Few studies have explored the moderating effect of subjective perception on the objective level and happiness.

This paper aims to make a contribution to the literature by establishing a theoretical framework to study the relationship between urban recreation environment and happiness. Firstly, we establish a structural framework of urban recreation environment to explore the direct impact of natural recreation environment and sociocultural recreation environment on happiness. More importantly, we analyze the indirect influence of objective background environment on happiness through the subjective satisfaction of urban recreation environment. In the empirical analysis, we discuss the direct and indirect effects of urban recreation environment on happiness through the structural equation model (SEM). Specifically, we mainly answer two questions: 1 . How does an urban recreation environment affect residents' happiness and whether a good urban recreation environment can enhance happiness? 2. How does the individual subjective evaluation of the recreation environment mediate the impact of the urban recreation environment on happiness?

We expand on existing research in two main ways. Firstly, previous studies on relevant topics rarely explored the impact of the recreation environment on happiness, and the mechanism of impact has been unclear. This paper discusses the influence mechanism of urban recreation environment on happiness in a comprehensive way. Second, we employ structural equation models to separate the mediator effects of the city's objective context on happiness through individual satisfaction with context. It is expected that this study will help deepen the understanding of the relationship between urban recreation environment and happiness, provide a new urbanization policy suggestion for Local governments in China, and further provide a basis for the construction of livable cities.

\section{Literature Review}

A recreation environment, as its name implies, is a place for recreational activities. It refers to a variety of space platforms, facilities and landscapes that can provide people with leisure and entertainment activities [14]. The excellent recreation environment of the city not only provides local residents with recreation activities, but also often acts as an attraction factor to attract tourists from all over the world [15]. The recreation environment 
is an important part of the urban system. A good recreation environment is conducive to the performance of recreation functions. For the research of urban recreation environment, the current research mainly focuses on the system analysis of recreation environment, recreation environment value evaluation, recreation environment carrying capacity and so on $[16,17]$. Happiness is the overall cognition and evaluation of residents on their quality of life [18]. The level of happiness of residents largely depends on the evolution of the external environment. The surrounding environment of individuals has an impact on happiness that cannot be ignored. So what is the relationship between the recreational environment and happiness?

For a long time, the urban recreation environment has been regarded as an important factor affecting happiness. However, from the theoretical point of view, its effect is uncertain, and empirical research has no consistent conclusion. Studies have shown that a high-quality urban recreation environment is conducive to improving the quality and tourism experience of tourist destinations, promoting the development of modern service industry represented by urban tourism, and promoting the construction of harmonious and livable cities [19]. In contrast, some studies have found that improvements in urban recreation environments have negative or insignificant effects on happiness $[15,20]$. A study has found that while the improvement of the urban recreation environment is conducive to the development of tourism, it also brings some uncertainties [21]. Meanwhile, another study found that a large number of tourists into the tourism destination may cause many social problems, such as environmental pollution, rising prices, uneven income, prominent security risks, and so on, which will affect the quality of life of urban residents, reduce the happiness of residents [22]. So what kind of recreation environment can enhance residents' happiness?

The factors that can be expected to influence the recreation environment factors of individual happiness can roughly be divided into two categories. The first is the influence of the natural environment. A study found a link between a natural environment and happiness and found that people in natural environments such as green spaces and parks are usually happier than those in urban architecture [23]. Another study found that environmental health is reflected in the damage to the environment caused by human production and living activities [24]. Human activities at the expense of the environment reduce the quality of the living environment, even endanger the physical health of residents, and have a negative impact on the evaluation of residents' happiness [18,25].

The second type of influencing factor is the social and cultural environment. The differences in the living environment caused by these factors are reflected in the inheritance of history and culture, characteristic cultural atmosphere, social tolerance and cultural quality of residents. Some studies have found that a good urban cultural environment can promote the healthy physical and mental development of citizens, so as to improve their sense of urban living, which is closely related to the quality of life of residents $[13,26]$. International frontier research shows that multi-culture is one of the most important urban elements of high-quality talents. Cities with thick historical and cultural atmospheres are conducive to improving urban taste and enhancing the cohesion of cities [27].

There are factors such as economic income, health status and the degree of democracy at the national level that also play an important role in happiness [28,29]. In fact, the factors that influence happiness are diverse. Socioeconomic factors, social class, policy systems, and geographic differences have all been shown to be associated with happiness [30]. From the perspective of many fields of happiness research, the urban recreation environment provides a new perspective for the research of happiness field. Based on the data of nearly ten thousand questionnaire surveys in 40 key cities in China, this paper studies the influence of urban leisure environment on happiness from the perspective of urban micro-behavior subjects. Previous studies have explored the direct impact of urban recreation environment on happiness through objective measurement, while few studies have measured the indirect impact mechanism of urban recreation environment on happiness through subjective measurement. Little is known about how the combination of objective 
and subjective influences is related to happiness. This paper proposes a comprehensive analytical framework to extend existing research.

\section{Theoretical Framework}

Firstly, this paper puts forward a hypothesis that the urban recreation environment affects happiness directly and indirectly through natural recreation environment and sociocultural recreation environment, and the objective urban recreation environment may further affect happiness through the subjective evaluation of urban recreation environment. This paper proposes a comprehensive analytical framework to extend existing research (Figure 1).

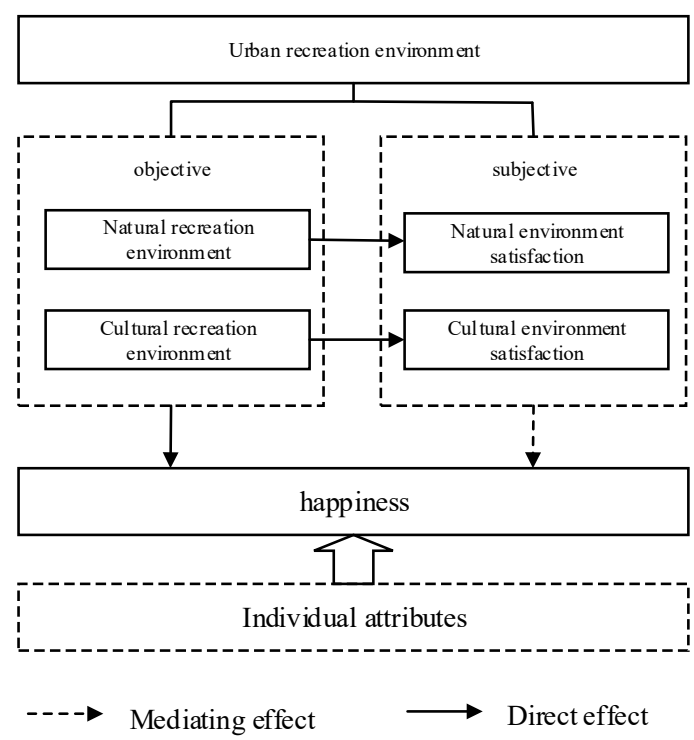

Figure 1. Conceptual framework of the study.

The urban natural recreation environment is the basis of urban tourism. At present, the world-famous happy cities not only pay attention to comfortable climate and beautiful natural environment, but also pay attention to urban ecological environment protection and environmental pollution control [31,32]. Natural background conditions such as beautiful natural landscape, vast water area and good ecological environment can add infinite charm to urban construction and make cities more livable [33-35]. Studies have shown that a good urban natural environment is conducive to providing people with a comfortable place to rest, which weakens the psychological constraints of urban buildings and facilitates people's mental relaxation [36]. Therefore, the natural environment is the basic factor constituting the urban recreation environment.

A sociocultural recreation environment is a kind of comprehensive cultural ecosystem. They include not only a humanistic environment and spiritual civilization atmosphere, but also a social moral atmosphere, social order, social welfare and social employment. At present, the research on urban living environment mainly focuses on service facilities, transportation and other fields, while the research on sociocultural environment is relatively few. History and culture are the soul and blood of a city. The sociocultural recreation environment is mainly embodied in the construction and cultivation of urban historical context and urban cultural tradition [37]. The strong historical and cultural atmosphere of the city is conducive to improving the urban taste [38].

In addition, it also includes the important role of individual attributes in happiness. We believe that personal characteristics such as age, gender, education, income and employment are significant correlates of happiness. The indirect effects of the urban recreation environment on happiness are more complex. The objective attribute of recreation environment first affects the residents' subjective evaluation of the recreation environment, and then affects happiness [38,39]. In other words, the subjective feeling of the recreation environment can mediate the influence of the recreation environment on happiness. 


\section{Research Design}

\subsection{Methods and Models}

We mainly use the Structural Equation Modeling (SEM) to verify the structural relationship between urban recreation environment and happiness. SEM is the equation reflecting the relationship between latent variables, which can be divided into measurement models and structural models [40]. The measurement model can reveal the relationship between measurable variables and latent variables, and the structural model can reveal the relationship between latent variables and latent variables. Combining the structure model with the path diagram of the measurement model can reflect the relationship between each latent variable of the research problem and the relationship between the latent variable and the measurable variable [41].

Main forms of structural equation model:

$$
\eta=\mathbf{B} \eta+\Gamma \xi+\zeta
$$

In the formula, $\eta$ is the endogenous latent variable vector and $\xi$ is the exogenous latent variable vector. $\zeta$ is the random interference term, reflecting the part of the equation that cannot be explained. B is a coefficient matrix about $\mathbf{m} \times \mathbf{n}$, which describes the mutual influence between endogenous latent variable $\eta$. $\Gamma$ is the coefficient matrix of the exogenous latent variable, which describes the influence of exogenous latent variable $\zeta$ on endogenous latent variable $\boldsymbol{\eta} . \mathbf{m}$ is the number of endogenous latent variables and $\mathbf{n}$ is the number of exogenous latent variables. AMOS was used for model testing.

According to the theoretical framework, this paper needs to test the influence of multiple media. Therefore, Structural Equation Modeling is adopted in this paper. The advantage of SEM is that it can capture the direct and indirect effects on the outcome variables. Figure 2 shows the model structure (Figure 2). The outcome variable is the happiness of the residents. Independent variables include the objective characteristics of urban natural recreation environment and sociocultural recreation environment. All of the independent variables have direct and indirect effects on happiness. Urban recreation environment satisfaction is a mediating variable, which plays a mediating role between objective recreation environment and happiness.

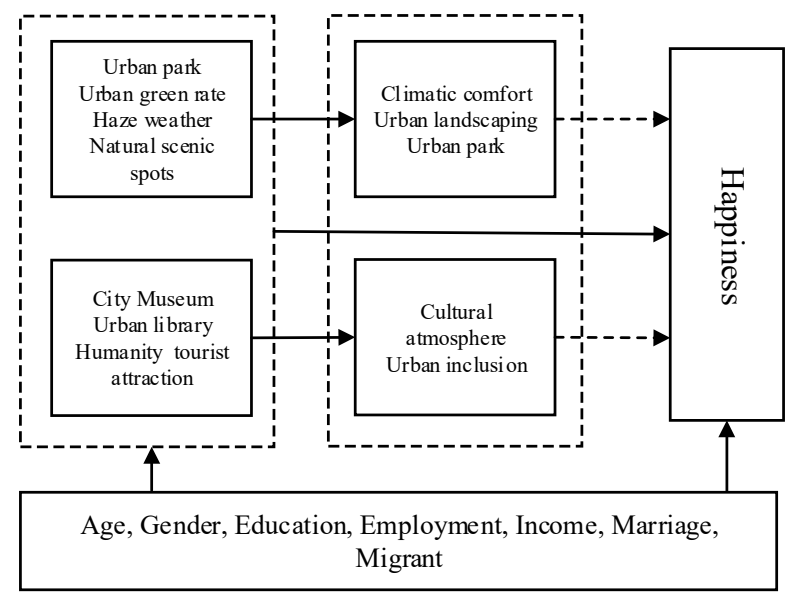

Figure 2. Model structure.

\subsection{Case Area}

In this study, we mainly selected 40 major cities in China, including 40 cities such as Beijing and Tianjin (Figure 3). The selected cities include coastal cities, central cities and western cities. Among them, there are 21 cities in the East, 8 cities in the middle and 11 cities in the West. Case cities are mainly selected from municipalities directly under the Central government, provincial capitals, sub-provincial cities and a few recognized livable and tourist cities, which will also be important agglomeration areas for China's 
urbanization development and tourism development in the future. Due to the influence of geographical and historical factors, the development of urbanization presents a state of regional imbalance, and there are great differences in the urban recreation environment.

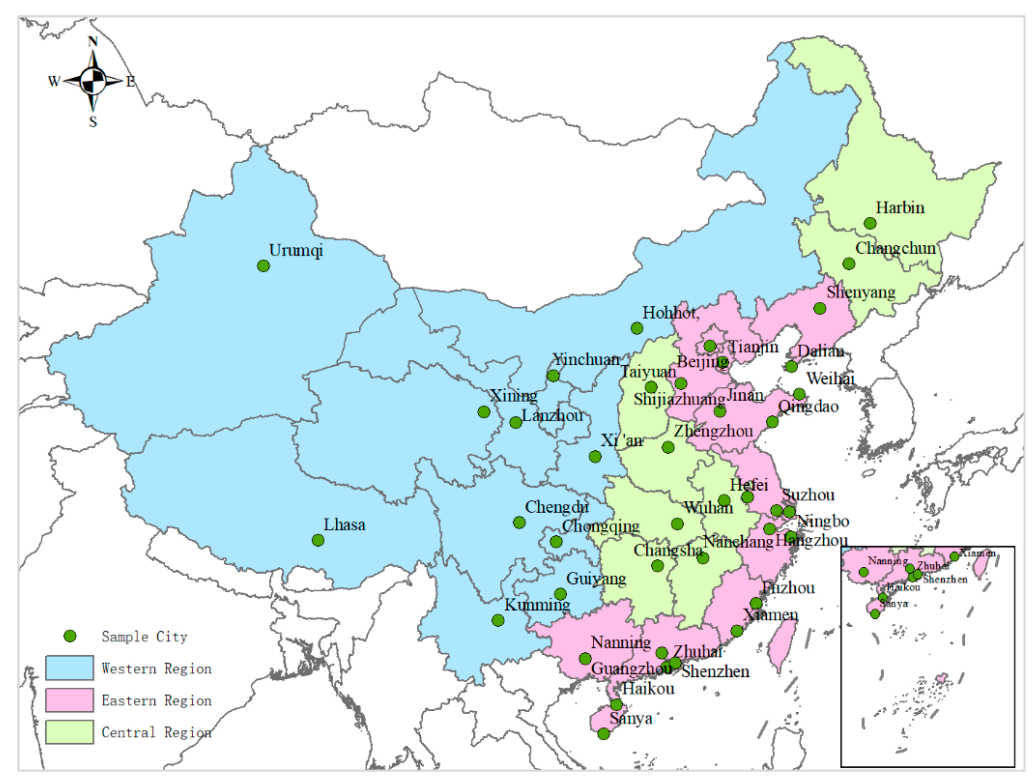

Figure 3. Case city. Note: These maps were drawn according to the standard map with drawing No. GS (2019) 1673, which was downloaded from the standard map service website of the Ministry of Natural Resources of the People's Republic of China. No modifications were made on the base map.

This paper selects 40 influential tourist cities in China as cases, mainly based on two considerations: Firstly, 40 cities are the regions with the fastest urbanization in China in the 21st century, and the research on the inter-city differences and influencing factors of residents' happiness in these regions is representative in China to some extent. Secondly, the case cities selected are abundant and various, including not only cities with good recreation environments such as Beijing, Shanghai and Guangzhou, but also cities with ordinary recreation environments such as Lhasa, Urumqi, Lanzhou and Xining. Cities vary due to natural background conditions, social and economic development level, cultural environment and regional functional orientation, which is conducive to the study of the formation mechanism of residents' happiness differences among cities.

\subsection{Data}

The questionnaire data were collected from 40 key cities carried out by Livable Cities Research Group of Institute of Geographic Sciences and Natural Resources Research, Chinese Academy of Sciences in 2015. Respondents were long-term residents who had lived in the city for more than half a year. The questionnaire recorded respondents' subjective evaluation of the urban living environment and well-being, as well as the socioeconomic attributes of the respondents. This research mainly by questionnaire, stratified sampling way according to the difference of administrative areas, the survey according to the 300 municipalities directly under the central government, the provincial capital and deputy provincial city, 250, according to the population size of 200 or 150 other cities of standard questionnaires, 12,000 questionnaires out, recycling effective questionnaire 9325, questionnaire efficiency up to 77.7\%. The objective data are from "2016 Statistical Yearbook of Chinese Cities", the "Official Website of National Tourism Administration" and the "Official Website of National Cultural Heritage Administration".

Table 1 shows the statistics for the variables used in this article. Resident happiness is based on the following survey questions: all things considered, how happy are you with your life as a whole? These responses were recorded on the five-point Licht scale, with " 1 = very unhappy", " 2 = unhappy", " $3=$ Fair", " $4=$ happy" and " $5=$ very happy". Most 
of the respondents (about 59.6 percent) were happy (or very happy) with their lives, and 36.9 percent reported an average level of happiness. Less than 4 percent of respondents were dissatisfied with their lives ( 3 percent) or very unhappy ( 0.5 percent). The majority of the sample were young and middle-aged, with about $50 \%$ aged between 20 and 39. There is not much difference between the sexes. More than 53 percent of the respondents studied at a university or college. The unemployed accounted for only 2.74 percent of the total. Most of the respondents were local residents, accounting for more than 63 percent.

Table 1. Variable description and summary statistics.

\begin{tabular}{|c|c|c|}
\hline Variable Properties & Variable Definition and Assignment & Proportions/Mean \\
\hline \multicolumn{3}{|l|}{ Dependent variable } \\
\hline Happiness (\%) & 1 = Very unhappy; 2 = unhappy $; 3=$ Fair; 4 = happy $; 5$ = Very happy & 0.5:3:36.9:33.6:26 \\
\hline Independent variable (objective) & Number of city parks & 114.95 \\
\hline \multirow{3}{*}{ Natural recreation environmental } & Urban greening rate & 39.32 \\
\hline & The number of good weather & 269 \\
\hline & The number of scenic spots in the city & 10.5 \\
\hline \multirow{3}{*}{ Sociocultural recreation environment } & Every hundred people have books in the library & 210.23 \\
\hline & Number of city museums & 39.49 \\
\hline & The number of key cultural relics under protection & 7.56 \\
\hline \multirow{5}{*}{ Independent variable (subjective) } & Climatic comfort: Residents' evaluation of climate comfort: $1 \sim 5$ & 3.06 \\
\hline & $\begin{array}{l}\text { Afforestation coverage in the city: Residents' evaluation of urban } \\
\text { green coverage rate: } 1 \sim 5\end{array}$ & 3.05 \\
\hline & $\begin{array}{l}\text { Assessment of the natural environment: Residents' evaluation of } \\
\text { urban park: } 1 \sim 5\end{array}$ & 3.07 \\
\hline & $\begin{array}{c}\text { Evaluation of urban cultural atmosphere: Residents' evaluation of } \\
\text { urban characteristic cultural atmosphere: } 1 \sim 5\end{array}$ & 3.08 \\
\hline & $\begin{array}{l}\text { Sociocultural environment evaluation: Residents' evaluation of urban } \\
\text { inclusion: } 1 \sim 5\end{array}$ & 3.05 \\
\hline Control variable & Marriage: Married; Unmarried & $62.1: 37.9$ \\
\hline \multirow{7}{*}{ Individual attributes } & Age: $\leq 20 ; 20-29 ; 30-39 ; 40-55 ; 56-60 ; 61-69 ; \geq 70$ & 10.7:18.5:27.1:19.9:12.3:11.4 \\
\hline & Gender: male; female & $51.7: 48.3$ \\
\hline & $\begin{array}{l}\text { Higher education: college degree or above; Low education: high } \\
\text { school or below }\end{array}$ & 46.1:53.9 \\
\hline & Census register (\%): Locality census register; Nonlocal census register & $64.8: 35.2$ \\
\hline & Family income: Respondents' annual household income & 4155 \\
\hline & Family size: The number of family members & 3.2 \\
\hline & Geographical location: Eastern region; Central region; Western region & $50.1: 19.7: 30.2$ \\
\hline
\end{tabular}

The independent variables of the model are depicted by the objective geographical environment characteristics such as the natural recreation environment and sociocultural recreation environment of the tourist city and the residents' subjective evaluation of these objective geographical environments. The specific explanatory variables are as follows:

The objective indexes of urban natural recreation environment are mainly reflected by urban parks, urban green rate, urban haze weather and urban scenic spots. The subjective evaluation of urban natural environment is mainly expressed by the residents evaluation of climate comfort, urban green coverage rate and the comprehensive evaluation of urban park.

The objective indicators of the urban sociocultural recreation environment are mainly expressed by the collections of the city library, the city museum and the key cultural relics protection units. The subjective evaluation of the sociocultural environment is mainly expressed by the residents' evaluation of the characteristic cultural atmosphere of the city they live in and the evaluation of the urban inclusion. 
Building on previous research, our model controlled for personal attributes such as age, gender, marital status, education, employment, and homeownership. It also includes Hukou to examine the impact of the Hukou system on happiness. The specific variables and their definitions are shown in Table 1.

\section{Empirical Findings}

In our study, the maximum likelihood estimation method on the covariance matrix was used to estimate the model fit. According to the test results of the model fitting degree, several important fitting indexes reached the ideal level, and the model fitting effect is good. On the whole, the goodness of fit indices were within the acceptable thresholds (see Table 2). CFI index considers values close to 1 as appropriate and those greater than 0.90 show the good fit of the model. A standard root-mean-square residual (SRMR) value less than $0.08(0.066)$ indicates an acceptable fitting. The root mean square error of approximation (RMSEA) is less than 0.08 (0.068).

Table 2. Evaluation of the overall goodness-of-fit of the structural equation model (SEM).

\begin{tabular}{ccc}
\hline Statistics & Fitted Value & Measurement Standard \\
\hline GFI (goodness of fit index) & 0.906 & $>0.9$ \\
NFI (normed fit index) & 0.923 & $>0.9$ \\
AGFI (adjusted goodness of & 0.852 & $>0.9$ \\
fit index) & 0.831 & $>0.9$ \\
CFI (comparative fit index) & 0.831 & $>0.9$ \\
IFI (incremental fit index) & 0.066 & $<0.08$ \\
RMR (root mean square & & $<0.08$ \\
residual) & 0.068 & \\
RMSEA (root mean square & &
\end{tabular}

The first four columns in Table 3 show the direct impact of the independent variables on the mediator and the outcome variables, and the last column shows the total impact on the outcome variables. Most of the independent variables have direct and indirect significant influences on happiness. Natural recreation environment and sociocultural recreation environment have different effects on happiness.

In terms of natural recreation environment, urban parks and green rates have a significant positive overall effect on happiness. Urban parks significantly affect the residents' perception of satisfaction and happiness with the natural environment. Urban green parks and open plazas are important places for residents' recreation and physical exercise. It is easy for residents to feel that they are living in a healthy environment due to its abundant vegetation and good greening. The rate of community green space can improve the residents' evaluation of the city's aesthetic degree. The increase of green rate is conducive to improving the natural environment of urban residential areas and creating a good activity space for residents.

Air pollution, such as haze, not only worsens the recreation environment, but also has a lot of negative impacts on cities. Relevant studies have found that the gloomy haze weather is likely to make people feel pessimistic and lost, making people tired, depressed, irritable and other emotional problems, more likely to induce depression. Haze exerts a subtle influence on happiness [42]. The impact of urban scenic spots on happiness is not obvious.

Scenic spots in the city are important attractions to attract tourists. A large number of urban scenic and historic interest area is of great significance to enhance the image of the city and improve the natural environment of the city. However, a large number of tourists gathering in cities tend to have a negative impact on the production and life of local residents, which will make the urban environment more complex, with more serious conditions such as noise and pollution, more traffic congestion, and at the same time bring some security problems. 
Table 3. Standardized coefficients of structural equations model.

\begin{tabular}{|c|c|c|c|c|c|}
\hline \multirow{2}{*}{ Variables } & \multirow{2}{*}{$\begin{array}{c}\text { Natural } \\
\text { Environment Satisfaction }\end{array}$} & \multirow{2}{*}{$\begin{array}{c}\text { Sociocultural } \\
\text { Environment Satisfaction }\end{array}$} & \multirow{2}{*}{$\begin{array}{c}\text { Happiness } \\
\text { (Direct Effect) }\end{array}$} & \multirow{2}{*}{$\begin{array}{c}\text { Happiness } \\
\text { (Direct Effect) }\end{array}$} & \multirow{2}{*}{$\begin{array}{c}\text { Happiness } \\
\text { (Total Effect) }\end{array}$} \\
\hline & & & & & \\
\hline \multicolumn{6}{|c|}{ Mediated Variable } \\
\hline City parks & $0.058 * * *$ & & $0.076^{*}$ & & 0.545 \\
\hline Urban greening rate & $0.071^{* * *}$ & & $0.029 * *$ & & 0.115 \\
\hline Haze weather & $-0.042 * * *$ & & $-0.003^{* *}$ & & -0.011 \\
\hline Scenic spots in the city & 0.026 & & 0.135 & & 0.101 \\
\hline library & & 0.061 & & -0.091 & 0.115 \\
\hline City museums & & $0.099 *$ & & 0.054 * & 1.267 \\
\hline $\begin{array}{l}\text { Cultural relics under } \\
\text { protection }\end{array}$ & & $0.017^{*}$ & & 0.061 & 0.545 \\
\hline \multicolumn{6}{|c|}{ Objective Variable } \\
\hline Climatic comfort & & & $0.815 *$ & & -0.023 \\
\hline Urban green coverage & & & 0.031 & & 0.000 \\
\hline Assessment of urban park & & & $0.003^{*}$ & & 0.245 \\
\hline $\begin{array}{l}\text { Evaluation of urban } \\
\text { cultural atmosphere }\end{array}$ & & & & $0.044^{*}$ & 0.399 \\
\hline Urban historical context & & & & 0.047 & 0.664 \\
\hline $\begin{array}{c}\text { Rent and purchase of a } \\
\text { house (Rent\#) }\end{array}$ & $0.033^{* *}$ & $0.031^{* * *}$ & $0.786^{*}$ & $0.008^{* *}$ & 0.045 \\
\hline Age & $0.033^{* *}$ & $0.003 * *$ & $0.739 * *$ & $0.008^{* *}$ & 0.264 \\
\hline Gender(male\#) & $0.021 * *$ & 0.044 & $0.053 * *$ & $0.106 *$ & 0.163 \\
\hline Education(Low education\#) & $0.117 * *$ & $0.047 * *$ & $0.058 * *$ & $0.113 * *$ & 0.108 \\
\hline Census register(local\#) & $0.016^{* *}$ & $0.058^{* *}$ & 0.004 & $0.341^{* *}$ & 0.176 \\
\hline Family income & $-0.036^{* *}$ & $-0.091 * *$ & $-0.028 * *$ & $-0.321 * *$ & 0.293 \\
\hline Family size & 0.807 & 0.055 & $0.026^{* *}$ & 0.022 & 0.240 \\
\hline
\end{tabular}

Note: ${ }^{*}$ significant at $10 \%$; ${ }^{* *}$ significant at $5 \%$; ${ }^{* * *}$ significant at $1 \%$.

In terms of sociocultural recreation environment, urban museums and key cultural relics protection units also have a certain impact on happiness. The impact of the cultural relic protection units on happiness is positive, indicating that residents in cities with rich historical and cultural heritage are more satisfied with the evaluation of happiness. The impact of city museums on happiness is also positive. The city museum is an important cultural leisure place in the city, which can meet the spiritual and cultural needs of residents and help improve their life satisfaction. Libraries have little impact on happiness. Libraries are places where the public can obtain knowledge and information. However, due to the development of electronic information technology, the popularity of electronic books has a great impact on the recreation facilities of libraries.

However, compared with the natural recreation environment, the influence of urban sociocultural recreation environment on happiness is significantly lower. It shows that the overall quality of China's urbanization is still at a lower level than that of developed cities in Europe and North America, and the consumption level of residents is still low. There is a price threshold for urban cultural products. The cultural products of high-income groups are in high taste pursuit, while the cultural products of low-income groups are less available, and they often attach importance to the comfort level of the natural environment.

Most independent variables have significant direct and indirect effects on happiness. After introducing the subjective variables of the natural recreation environment, the significance of the objective variables of the natural environment was reduced. After adding the subjective satisfaction of the sociocultural recreation environment, it was also found that the indicators of the objective sociocultural environment were no longer significant. The two mediating variables were significantly positively correlated with the outcome variables. This indicates that there is a mediating effect between the subjective evaluation of natural recreation environment and sociocultural recreation environment.

For individual demographic and socioeconomic characteristics, most of the results are basically consistent with existing research. The happiness of the female group is significantly higher than that of the male group, which may be due to the fact that men need to face greater family and social responsibilities and mental pressure than women 
in the city [39]. Age has no significant influence on residents' happiness. Education has a certain influence on residents' happiness. The higher the educational level, the higher the happiness. In terms of family factors, income is negatively correlated with happiness. This further verifies the practice of the "Easterlin paradox" in China.

Due to the difference in the geographical environment, the urban recreation environment in China is relatively good in the eastern region but relatively poor in the central and western regions. In order to analyze the impact of urban heterogeneity on happiness, we further analyzed the differences in urban happiness levels in different locations (Figure 4). The results show that the happiness in the eastern region with a better urban recreation environment is not higher, which indicates that the relationship between recreation environment preparation happiness is non-linear, and the quality urban recreation environment does not correspond to the higher happiness. The happiness of the middle-class residents living in the eastern cities is lower, and that of low-income immigrants living in the western regions is also lower. The happiness of the low-income residents living in the eastern region and the high-income residents living in the central region is relatively higher. It indicates that the urban recreation environment has a more obvious influence on the happiness of middle and low-income immigrants. On the other hand, it also indicates that middleincome and low-income groups have a higher sensitivity to the recreation environment, while high-income groups have a lower sensitivity to the recreation environment. The high-income groups have the ability to improve their living environment to enhance their happiness, while the low-income group may not be able to do so.

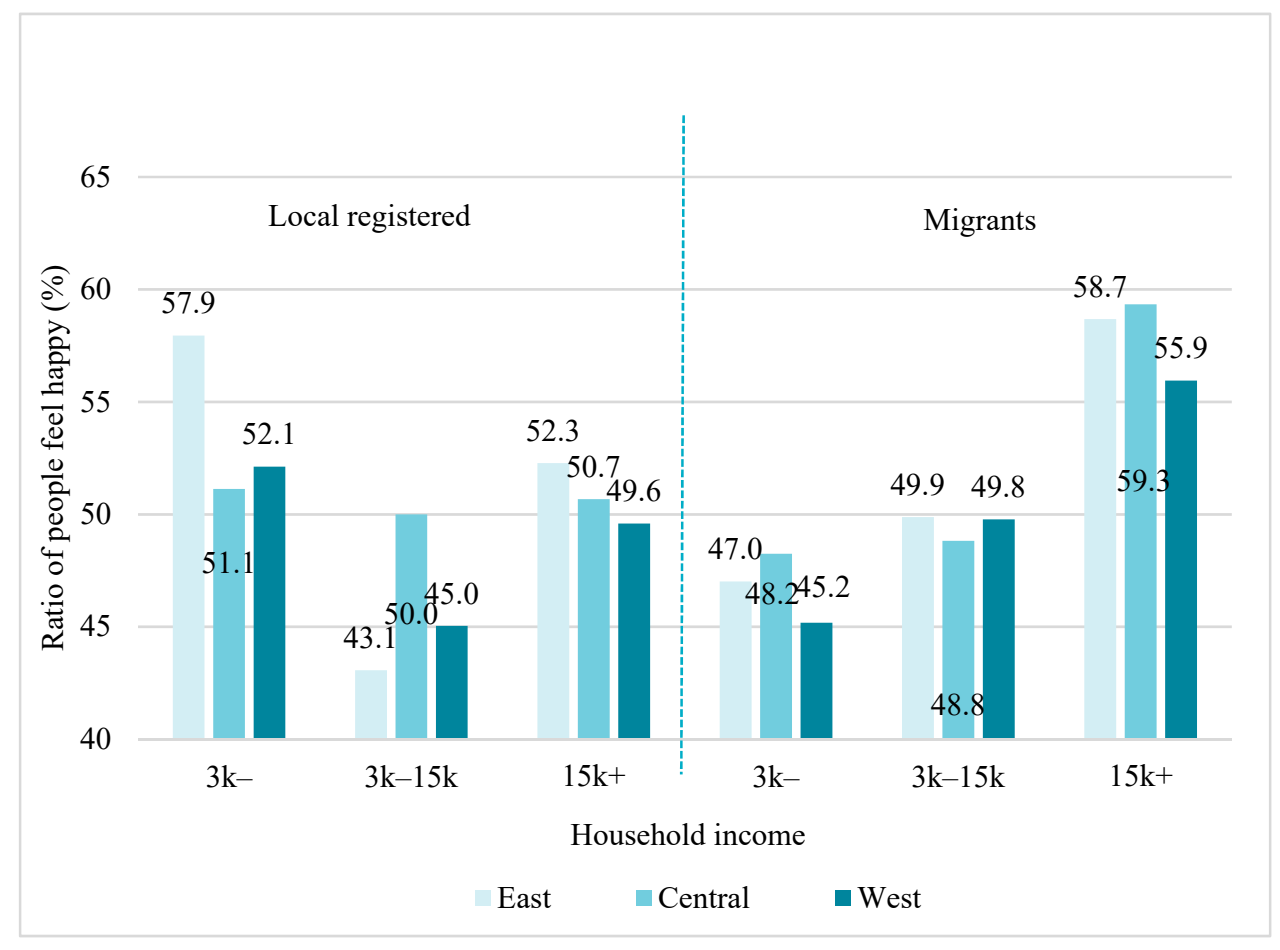

Figure 4. Ratio of happy people in different location cities.

\section{Conclusions}

Whether a good urban recreation environment can improve happiness is an emerging topic in academic circles. At present, there is still a big gap in the study of residents' quality of life from the perspective of the urban recreation environment. In the context of rapid urbanization, the study of the urban living environment has attracted more attention from scholars. Previously, scholars mainly focused on the environmental factors of urban background, but rarely considered the impact of urban recreation environment development on happiness. 
Based on the extensive questionnaire survey data of 40 cities in China, this paper studies the influence of urban recreation environment on residents' happiness from the perspective of individual subjective perception. In addition, the SEM model was used to estimate the mediating effect of individual subjective feelings. There are three main findings.

(1) The objective indicators of both natural and sociocultural recreation environment have an important impact on happiness, but the impact of the natural environment is greater than that of the sociocultural environment, which may be related to the fact that the sociocultural environment is less valued in the process of urbanization in China.

(2) Individual satisfaction with urban recreation environment is the mediating effect of the relationship between urban objective recreation environment characteristics and happiness. This might indicate that an objective recreation environment does not affect happiness directly but indirectly through its impact on the satisfaction of the recreational environment.

(3) The influence of urban location happiness is non-linear, and the influence of income on happiness is heterogeneous. Low-income groups are more sensitive to the recreation environment, while high-income groups are less sensitive to the recreation environment.

\section{Discussion}

This study explores the effects of objective recreation environment and subjective recreation environment on subjective well-being. The natural recreation environment is an important part of exploring urban recreation functions. Many works of literature have found that a natural recreation environment has a significant impact on happiness. [10,43] This is similar to the results of this paper, and the social and cultural recreation environment has a relatively limited effect on happiness. The possible reason is that China may be in the current urbanization quality is not high, the social and cultural recreation function of cities is not perfect, and can not meet the needs of residents.

The impact of subjective recreation environment assessment on life satisfaction is greater than that of an objective recreation environment, which is consistent with the results of previous studies $[44,45]$. The indirect effect of objective recreation environment on happiness, which is expressed by subjective evaluation of recreation environment, is the most powerful way of the relationship between recreation environment and happiness. It is inferred that both a poor recreational environment and the perception of a poor recreational environment (poor subjective environmental rating) have a negative impact on happiness. This may be an important factor affecting residents' happiness.

The happiness level of residents in the eastern region with a better recreational environment is not high, which is not consistent with the existing research. Most studies have found a positive relationship between quality recreation environment and happiness level $[35,46]$. At present, the main reasons for the low happiness of Chinese residents in cities with a good recreational environment may be the high housing price, environmental pollution and traffic congestion. High-quality recreation environment is not enough to relieve their life pressure.

Policymakers should be interested in the results. Urban natural recreation environment has a more obvious influence on happiness. Urban parks and urban water space are not only important urban landscape, but also important places of urban residents' activity space. It plays an important role in improving the living environment quality of residents. In the future, the city should pay attention to the optimal layout of urban parks and urban green space in the construction of built-up areas, enhance the aesthetic value and recreation value of the natural landscape, and build a green, ecological, harmonious and pleasant livable city.

In the major developed cities of Europe and the United States, urban cultural elements are an important feature of urban development, and urban cultural atmosphere and cultural products can enhance the urban taste. Urban planning and construction should not only pay attention to the protection of historical context, but also pay attention to the needs of residents for sociocultural products. Although the current urban sociocultural recreation 
environment in China has a low impact on happiness, and the consumption level of Chinese residents cannot reach the level of developed cities in the West, the future development and prosperity of cities need to strengthen the protection of urban history and culture, the construction of museums and the innovation of cultural products.

A high-quality urban recreation environment must be natural and balanced development of the social culture, comprehensive development of complement each other. Therefore, in the process of urban planning and development, it is necessary to overcome the adverse effects brought by the recreational environment, increase the capital investment in urban recreation infrastructure, improve the level of software and hardware facilities for recreational activities, enhance the attraction of urban tourism, and provide a comfortable living environment for urban residents. It can make urban residents feel more belonging.

The construction of a recreation environment needs to meet the needs of different groups. In future recreation environment construction, it is necessary to fully grasp the demand of low-income groups and immigrants for recreation facilities and services, and the supply of recreation services should adapt to the price threshold of low-income groups and immigrants. For high-income groups, it is necessary to meet the demand for their characteristic recreational facilities services.

The study has some limitations. First, there are some limitations in our data. Relevant environmental indicators of the urban recreation environment are not very comprehensive. Due to limited data, indicators such as urban climate environment and land environment cannot be taken into account in natural environmental factors. Second, this study analyzes and studies the effect of urban recreation environment on happiness from the macro level, while the interaction mechanism between urban recreation environment and happiness from the micro-level needs to be further explored in combination with case cities. Despite these limitations, the study provides important insights into the recreational environment and happiness of Chinese cities.

Author Contributions: Writing-original draft, L.K.; funding acquisition, Z.Y. and F.H.; supervision, Z.Y. and F.H. All authors have read and agreed to the published version of the manuscript.

Funding: This study was supported by the Second Tibetan Plateau Scientific Expedition and Research Program, Grant No. (2019QZKK1004) and the National Natural Science Foundation of China (No. 41971192).

Institutional Review Board Statement: Not applicable.

Informed Consent Statement: Not applicable.

Data Availability Statement: Not applicable.

Conflicts of Interest: The authors declare no conflict of interest.

\section{References}

1. Onose, D.A.; Ioj, I.C.; Ni, M.R.; Vnu, G.O.; Popa, A.M. Too old for recreation? how friendly are urban parks for elderly people? Sustainability 2020, 12, 790. [CrossRef]

2. Derek, M.; Wozniak, E.; Kulczyk, S. Clustering nature-based tourists by activity. Social, economic and spatial dimensions. Tour. Manag. 2019, 75, 509-521. [CrossRef]

3. Chen, J.; Chen, S. Mental health effects of perceived living environment and neighbourhood safety in urbanizing China. Habitat Int. 2015, 46, 101-110. [CrossRef]

4. Zonneveld, W.; Klaasen, I. Evaluating the new charter of Athens 2003. Built Environ. 2012, 38, 453-458. [CrossRef]

5. Clark, A.E.; Frijters, P.; Shields, M.A. Relative income, happiness, and utility: An explanation for the Easterlin paradox and other puzzles. J. Econ. Lit. 2008, 46, 95-144. [CrossRef]

6. Ojala, M. Coping with Climate Change among Adolescents: Implications for Subjective Well-Being and Environmental Engagement. Sustainability 2013, 5, 2191-2209. [CrossRef]

7. Dolan, P.; Peasgood, T.; White, M. Do we really know what makes us happy? A review of the economic literature on the factors associated with subjective wellbeing. J. Econ. Psychol. 2008, 29, 94-122. [CrossRef]

8. Dong, H.; Qin, B. Exploring the link between neighbourhood environment and mental wellbeing: A case study in Beijing, China. Landsc. Urban Plan. 2017, 164, 71-80. [CrossRef] 
9. Dean, J.W. National welfare and individual happiness: Income distribution and beyond. J. Policy Model. $2007,29,567-575$. [CrossRef]

10. Deeming, C.; Hayes, D. Worlds of welfare capitalism and wellbeing: A multilevel analysis. J. Soc. Policy 2012, 41, 811-829. [CrossRef]

11. Asadullah, M.N.; Xiao, S.; Yeoh, E. Subjective well-being in China, 2005-2010: The role of relative income, gender and location China Econ. Rev. 2018, 48, 83-101. [CrossRef]

12. Liu, Z.; Liu, S.; Qi, W.; Jin, H. Urban sprawl among Chinese cities of different population sizes. Habitat Int. 2018, 79, 89-98. [CrossRef]

13. Gorina, E.; Agadjanian, V.; Zotova, N. Migrant women's economic success in Russia: Objective reality and subjective assessment. J. Ethn. Migr. Stud. 2014, 44, 1584-1603. [CrossRef] [PubMed]

14. Shani, A. Tourism, recreation and sustainability: Linking culture and the environmemen. Tour. Anal. 2010, 15, 613-614.

15. Loo, C.; Poulos, H.; Workman, J.; Deboer, A.; Michaels, J. How much is a healthy river worth? the value of recreation-based tourism in the connecticut river watershed. Ethics Policy Environ. 2015, 18, 44-59. [CrossRef]

16. Zhong, L.; Deng, J.; Song, Z.; Ding, P. Research on environmental impacts of tourism in china: Progress and prospect. J. Environ. Manag. 2011, 92, 2972-2983. [CrossRef]

17. Buckley, R. Tourism and environment. Soc. Sci. Electron. Publ. 2011, 36, 296. [CrossRef]

18. Olya, H.G.T.; Alipotna, H. Developing a climate-based recreation management system for a mediterranean island. Fresenius Environ. Bull. 2015, 24, 1-24.

19. Liu, J.; Nijkamp, P.; Huang, X.; Lin, D. Urban livability and tourism development in China: Analysis of sustainable development by means of spatial panel data. Habitat Int. 2017, 68, 99-107. [CrossRef]

20. Kim, K.; Uysal, M.; Sirgy, M.J. How does tourism in a community impact the quality of life of community residents? Tour. Manag. 2013, 36, 527-540. [CrossRef]

21. Freitas, D.C.; Scott, D.; McBoyle, G. A Second Generation Climate Index for Tourism (CIT): Specification and Verification. Int. J. Biometeorol. 2008, 52, 399-407. [CrossRef]

22. Haija, A.A.A. Jordan: Tourism and conflict with local communities. Habitat Int. 2011, 35, 93-100. [CrossRef]

23. Mackerron, G.; Mourato, S. Happiness is greater in natural environments. Glob. Environ. Chang. 2013, 23, 992-1000. [CrossRef]

24. Smyth, R.; Mishra, V.; Qian, X. The environment and well-being in urban China. Ecol. Econ. 2008, 68, 547-555. [CrossRef]

25. Fischer, R.; Vliert, E.V.D. Does climate undermine subjective well-being? a 58-nation study. Personal. Soc. Psychol. Bull. 2011, 37, 1031. [CrossRef]

26. Wu, W. Does public investment improve homeowners' happiness: New evidence based on micro surveys in Beijing. Urban Stud. 2014, 51, 75-92. [CrossRef]

27. Florida, R. The economic geography of talent. Ann. Assoc. Am. Geogr. 2002, 92, 743-755. [CrossRef]

28. Weziak-Bialowolska, D. Quality of life in cities-Empirical evidence in comparative European perspective. Cities 2016, 58, 87-96. [CrossRef]

29. Wilkinson, R.; Pickett, K. The Spirit Level: Why Greater Equality Makes Societies Stronger; Bloomsbury Press: New York, NY, USA, 2009.

30. Wu, H.; Tam, T. Economic development and socioeconomic inequality of wellbeing: A cross-sectional time-series analysis of urban China, 2003-2011. Soc. Indic. Res. 2015, 124, 401-425. [CrossRef]

31. Matzarakis, A.; Hammerle, M.; Koch, E. The Climate Tourism Potential of Alpine Destinations Using the Example of Sonnblick, Rauris and Salzburg. Theor. Appl. Climatol. 2012, 110, 645-658. [CrossRef]

32. Arifwidodo, S.D.; Perera, R. Quality of life and compact development policies in Bandung, Indonesia. Appl. Res. Qual. Life 2011, 6, 159-179. [CrossRef]

33. Galea, S. Urban built environment and depression: A multilevel analysis. J. Epidemiol. Community Health 2005, 59, 822-827. [CrossRef] [PubMed]

34. Li, Z.; Wu, F. Residential satisfaction in china's informal settlements: A case study of Beijing, Shanghai, and Guangzhou. Urban Geogr. 2013, 34, 923-949. [CrossRef]

35. Liu, Y.; Zhang, F.; Wu, F.; Liu, Y.; Li, Z. The subjective wellbeing of migrants in Guangzhou, China: The impacts of the social and physical environment. Cities 2017, 60, 333-342. [CrossRef]

36. Millward, A.A.; Sabir, S. Benefits of a forested urban park: What is the value of Allan Gardens to the city of Toronto, Canada? Landsc. Urban Plan. 2011, 100, 177-188. [CrossRef]

37. Chen, L.; Dang, Y.; Zhang, W. Satisfaction on urban cultural environment and influencing factors. Prog. Geogr. 2017, 36, 1119-1127.

38. Ma, J.; Dong, G.; Chen, Y.; Zhang, W. Does satisfactory neighbourhood environment lead to a satisfying life: An investigation of the association between neighbourhood environment and life satisfaction in Beijing. Cities 2018, 74, 229-239. [CrossRef]

39. Dang, Y.; Chen, L.; Zhang, W.; Zheng, D.; Zhan, D. How does growing city size affect residents' happiness in urban China? A case study of the Bohai rim area. Habitat Int. 2020, 97, 102-120. [CrossRef]

40. Tong, D.; Yuan, Y.; Wang, X. The coupled relationships between land development and land ownership at China's urban fringe: A structural equation modeling approach. Land Use Policy 2021, 100, 104925. [CrossRef]

41. Yang, Y.; Green, S.B. A note on structural equation modeling estimates of reliability. Struct. Equ. Model. Multidiscip. J. 2010, 17, 66-81. [CrossRef] 
42. Huang, W.; Tan, J.; Kan, H.; Zhao, N.; Song, W.; Song, G. Visibility, air quality and daily mortality in shanghai, china. Sci. Total Environ. 2016, 407, 3295-3300. [CrossRef] [PubMed]

43. Winters, J.V.; Li, Y. Urbanisation, natural amenities and subjective well-being: Evidence from US counties. Urban Stud. 2017, 54, 1956-1973. [CrossRef]

44. Greif, M. The intersection of homeownership, race and neighbourhood context: Implications for neighbourhood satisfaction. Urban Stud. 2014, 52, 50-70. [CrossRef]

45. Phillips, D.; Siu, O.; Yeh, A.; Cheng, K. The impacts of dwelling conditions on older persons' psychological well-being in Hong Kong: The mediating role of residential satisfaction. Soc. Sci. Med. 2005, 60, 2785-2797. [CrossRef]

46. Shields, M.; Price, S.; Wooden, M. Life satisfaction and the economic and social characteristics of neighbourhoods. J. Popul. Econ. 2009, 22, 421-443. [CrossRef] 